\title{
Reflexão e identidade profissional do professor de LE: Que histórias contam os futuros professores?
}

João A. Telles

UNESP - Universidade Estadual Paulista

Este artigo relata os resultados de um estudo realizado com alunas de graduação em Letras, Português - Língua Estrangeira (Inglês, Espanhol, Italiano, Japonês, Francês e Alemão). Objetivou verificar as metáforas, regras da prática e princípios que as alunas identificaram durante um processo de reflexão sobre suas formações profissionais. Foi possível identificar o impacto desses elementos em seus processos individuais de desenvolvimento de identidades como professoras. O resultado foi um conjunto de histórias biográficas escritas (fontes de experiências) nas quais as participantes se baseavam para constituir suas identidades profissionais como professoras de línguas estrangeiras. Nesses processos, elas puderam construir ligações significativas entre os aspectos teóricos evidenciados nas leituras que realizaram durante o período da pesquisa e os vários eventos marcantes de suas narrativas orais acerca da carreira profissional. A associação dos vários aspectos de suas histórias pessoais às questões teóricas que foram discutidas durante a pesquisa revela processos de construções de identidades profissionais como professoras de línguas estrangeiras.

This paper reports on a study conducted with female pre-service teachers along the four years of their undergraduate program with major in Portuguese and a Foreign Language (English, Spanish, Italian, Japanese, French or German). The objective was to examine the metaphors, rules of practice and principles that they brought to their process of reflection upon their professional development. I have also identified the roles of these elements in their individual processes of developing their professional identity as teachers. The results were a set of written biographical stories (sources of experiences) in which the participants base themselves to constitute their professional identities as teachers of foreign languages. Within this process, they were able to construct meaningful connections between the theoretical aspects of readings that were undertaken during the research period and the many marking events of their oral narratives about their professional development. The association of the various aspects of their personal stories with the theoretical issues that were discussed during the research reveals processes of professional identity construction as teachers of foreign languages. 


\section{Introdução}

A inspiração para realizar a pesquisa aqui relatada e escrever um artigo acerca da identidade profissional do professor de línguas estrangeiras advém de meu interesse pessoal, nesses últimos anos, pelas razões que levam jovens a optarem pelo ofício de ensinar uma língua estrangeira. Para professores de cursos de Letras que, como eu, têm encontrado as mais esdrúxulas motivações entre os alunos (deveria dizer "resignações", pois, para alguns, o curso funciona como um tapa-buracos de um vazio existencial, frustração por não ter passado no vestibular para um outro curso socialmente mais prestigiado ou, ainda, de uma ausência de objetivos de vida), uma preocupação constante é saber se o desenrolar do currículo de graduação ajudará aqueles que "caíram de pára-quedas" a encontrar o que existe de belo e artístico no exercício de ensinar as línguas e as culturas de outros povos às crianças e aos jovens brasileiros. Aprender uma língua estrangeira faz parte de uma educação para o reconhecimento das diferenças - é o próprio encontro com a diferença e as possíveis estratégias para com ela lidar. Há algo de lúdico (e esquizofrenicamente divertido) ao falarmos uma língua estrangeira; algo como vestir uma fantasia, pensarmos e nos comportarmos como "O outro diferente", para depois retornarmos àquilo que temporariamente somos. Assim, refletir narrativamente (contando histórias) sobre a natureza do conjunto de elementos que funcionaram e funcionam como referências para a construção de nossas múltiplas facetas como professores de línguas pode contribuir para uma conscientização do papel social dessa profissão e para um sentimento de pertencer a essa comunidade. Acredito que tal reflexão seja relevante para professores em formação inicial e formação continuada, assim como para educadores de professores.

Diante dessas motivações iniciais para a realização deste estudo, suas bases metodológicas estão na Pesquisa Narrativa (CONNELLY \& CLANDININ, 1988, 1990, 1999; CLANDININ \& CONNELLY, 1995, 2000; TELLES, 1999, 2000, 2002a), por meio da qual os participantes da pesquisa narram histórias de suas experiências pessoais, profissionais e sociais. As alunas de Letras, participantes deste projeto, narram suas histórias acadêmicas. 


\section{Fundamentação teórica}

\section{Os conceitos de identidade e de identidade profissional adotados neste trabalho}

Segundo Guattari \& Rolnik (1996), a questão da identidade é complexa. Em parte pelo significado cristalizado que adquiriu em nossa sociedade e, também, pela padronização dos processos que a constitui (p.74). Em ambos os casos, há a tendência de se compreender a identidade como algo cristalizado, "endurecido" - um território fechado em si mesmo.

Neste trabalho, a identidade profissional, entretanto, está sendo pensada como um conjunto de referências, de marcas existenciais que compõem a identidade profissional das participantes. Diferentemente do modo homogêneo de produção das identidades na sociedade atual, a identidade profissional a qual me refiro neste estudo leva em conta traços muito particulares da experiência pessoal de cada participante: sua história de vida, suas memórias e os eventos marcantes de suas vidas. Isto é, não há uma única marca ou traço de vida que está sendo considerado como a "verdade" do ser-professor, de modo a constituir sua identidade profissional. Ao contrário, tal identidade é múltipla, diferenciada e dinâmica. Ela se produz em contextos de situação de aprendizagem (dentro ou fora da escola, da sala de aula). Dependerá, portanto, de algumas referências universais, como a definição de contexto de aprendizagem, questões de gênero, etc, mas não se reduz a elas. Como pode ser observado pelos excertos das participantes, para cada uma, além desses "universais" que aqui não assumem o valor de "verdade absoluta", há aquelas referências que dizem respeito à própria vida da participante. Em alguns casos, elas podem ser semelhantes ou não às experiências de outros professores. Por fim, a questão da identidade se resume em um conjunto de elementos que são referencias para a prática do professor, sejam eles teóricos, empíricos ou mesmo trazidos pela participante, antes mesmo de ela imaginar-se um dia tornar-se professora.

Segundo Guattari \& Rolnik (1996), a subjetividade é um agenciamento coletivo de enunciação (p. 31). Ou seja, é um conjunto de sinais, signos, símbolos que se constroem coletivamente em cada cultura em diferentes contextos históricos. Assim, por exemplo, a identidade nacional é um nível territorializado da subjetividade de todos aqueles 
que nascem no Brasil. Entretanto, a identidade é apenas um nível territorializado, no sentido de cristalizado no tempo e espaço, da subjetividade. Entretanto, essa identidade pode se desterritorializar, isto é, desmanchar-se e ser atravessada por outros níveis de composição da subjetividade. Assim, há várias formas de ser brasileiro, do mesmo modo que há diversas formas de ser professor, etc. O mesmo se pode dizer de uma subjetivação negra, isto é, de todos aqueles que nascem negros. É evidente que aí há uma identidade territorializada nessa subjetivação. Mas, é claro, uma certa negritude pode atravessar seja aquele que se identifica como negro, ou aquele que se identifica ao negro (uma pessoa branca, por exemplo). A negritude, um outro nível de subjetivação, não se reduz nem tampouco se localiza na identidade, mas antes, a atravessa, a recorta e permite, em muitos casos, transmutá-la. Do mesmo modo, não basta formar-se curricularmente como professor. É preciso, antes, deixar-se atravessar pela "pedagogia", pelo "querer ensinar-aprender", fazendo parte da identidade profissional do professor.

\section{A relação narrativa - identidade neste estudo: Uma abordagem narrativa}

Connelly \& Clandinin (1999) apresentam uma interessante abordagem à questão da identidade do ponto de vista narrativo. Para esses autores, as identidades têm suas histórias - são histórias pelas quais vivemos ou "construções narrativas que adquirem formas no desenrolar de nossas vidas e que podem, como é comum acontecer com tais construções, se solidificar em entidades fixas (uma construção narrativa imutável), ou então continuar a crescer e a se transformar. Essas construções podem ser (e quase certamente o são), múltiplas, dependendo das situações de vida nas quais a pessoa se encontra" (p. 95). Assim, como histórias que são por nós vivenciadas, as identidades têm naturezas, tendem a mostrar suas diferentes facetas (dependendo da situação na qual nos encontramos) e muitas vezes nos dão a impressão de serem imutáveis.

Neste estudo, por meio das narrativas de vida escritas pelas professoras em formação inicial, tento buscar as naturezas de suas identidades profissionais e as condições em que são construídas, sustentadas e transformadas. É importante apontar para o fato de que o próprio processo de construção e redação das narrativas parece ter 
contribuído para a explicitação dessas identidades, como poderá ser constatado pelos excertos apresentados. O que tento fazer é um rastreamento dos modos de construção das naturezas das identidades, para que possamos descontruir o caráter de entidades por vezes imutáveis (o instinto materno, assassino, etc.) e identificáveis (você é pobre, você é negro, ser professora é profissão de mulher, etc.) das identidades a nós impostas pela sociedade.

\section{O Estudo}

O contexto escolhido para o desenvolvimento do projeto foi um curso universitário de graduação em Letras - Línguas Estrangeiras (quatro anos) de uma universidade estadual. O Departamento de Letras Modernas da universidade se empenha na licenciatura de professores em seis línguas estrangeiras: Inglês, Francês, Espanhol, Alemão, Italiano e Japonês. O trabalho reflexivo, por meio de narrativas de vida, foi realizado ao longo de três anos, com doze alunas, graduandas em Letras - Línguas Estrangeiras (inglês, francês, espanhol e japonês, no caso).

\section{Perguntas de Pesquisa}

Este estudo buscou responder a duas perguntas de pesquisa:

- Em que histórias (fontes de experiências prévias) se apóiam algumas alunas de Letras para constituírem suas identidades profissionais como professoras de línguas estrangeiras?

- Como as alunas participantes respondem à reflexão acerca dos processos de constituição de suas identidades como professoras de línguas estrangeiras?

\section{Instrumentos de coleta de material documentário}

O material documentário consistiu em historias das doze participantes acerca de suas experiências pessoais, acadêmicas e na língua estrangeira (aprendizagem e, se possível, o ensino da língua). Os instrumentos primários de coleta do material documentário foram as narrativas orais que as participantes apresentaram para o grupo de pesquisa. Ao final do projeto, o número de participantes caiu para oito, por várias razões: interesses, tempo disponível, tipo de trabalho, desistência do curso, etc. Como coordenador do projeto, fui o primeiro participante 
a apresentar minha própria narrativa de vida e minhas próprias histórias relacionadas à aquisição, à aprendizagem e ao ensino do Inglês (a língua na qual me graduei e a qual permaneci lecionando até o final do estudo).

Outras fontes de material documentário foram os diários e as entrevistas semi-estruturadas, gravadas em áudio e em vídeo. Nos diários, as alunas registraram suas reflexões acerca das aulas que estavam tendo no curso de graduação, acerca do processo de pesquisa e, se fosse possível, acerca de suas experiências de ensino da língua na qual pretendiam se graduar. Após uma análise interpretativista e compartilhada com cada uma das participantes, organizei uma série de perguntas que as auxiliaram na reconstrução de significados das experiências relatadas.

\section{Procedimentos de coleta e análise do material documentário}

O tratamento dado a esses textos foi de cunho interpretativista (SCHWANDT, 1998; GLESNE \& PESHKIN, 1992; TELLES, 2002b) e muito próximo à Fenomenologia Hermenêutica apresentada por Van Manen (1990) e RICOEUR (1984). A Fenomenologia Hermenêutica se ocupa em estudar o fenômeno do ponto de vista da participante, de como ele se apresenta para ela. O enfoque recai sobre as essências (qualidades) da experiência vivida por ela.

No processo de análise dos dados, preocupei-me em descrever e interpretar os significados que as participantes puderam ter de suas experiências relatadas. Van Manen (1990) ainda aponta que Fenomenologia Hermenêutica é o estudo humano e científico do fenômeno, uma prática de questionamento, uma procura do que significa ser humano, além de ser uma atividade poetizadora (p.13). Van Manen (1990) segue uma linha fenomenológica que acredita que a consciência é o único acesso que os seres humanos têm ao mundo. De acordo com esse paradigma, tudo que podemos saber deve estar presente na consciência, seja isso real ou até imaginário. Como diz o autor: "o que estiver fora da consciência deverá estar fora dos limites de nossa possível experiência vivida [ou, então, não é vivida como tal]" (p.13, minha inserção). Todas as minhas atividades de coleta de material documentário objetivaram provocar nas participantes uma retrospecção de suas experiências vividas durante o processo de pesquisa”.

O procedimento básico de abordagem dos textos descritivos das transcrições foi localizar segmentos no corpo do texto nos quais a 
participante descrevesse suas experiências vividas. Uma vez localizados esses segmentos descritivos, tentei inferir a interpretação que a participante tivesse de sua experiência, por meio de sua descrição. Esse processo não somente partiu da participante, mas também de mim, o analista do texto, dentro de meu próprio borizonte hermenêutico (GADAMER, 1986). Tal horizonte é definido pela minha própria história, a qual é composta por minhas experiências. Tento, dessa maneira, entrar em um diálogo bermenêutico (op.cit.) com o texto, lançar minhas interpretações acerca das interpretações que a participante apresentou de sua experiência. Em fase posterior, minhas interpretações foram apresentadas às participantes para que as mesmas pudessem convalidá-las.

Os últimos passos dessa análise interpretativista foram, primeiramente, a preparação de memorandos e o próprio processo de escrever este trabalho, no qual relato o corpo de significados que tivemos de nosso trabalho de pesquisa.

\section{Resultados}

O resultado do projeto foi um conjunto de narrativas escritas. Nelas, as participantes contam suas histórias nas quais, como alunas de Letras, se apóiam para constituir suas identidades de professoras de línguas estrangeiras. No processo, as alunas foram capazes de estabelecer conexões e significados entre os aspectos teóricos das leituras acerca de formação profissional de professores de línguas (realizadas durante a pesquisa) e os diversos eventos marcantes de suas narrativas orais acerca do desenvolvimento pessoal de cada uma. Ao remeter os vários aspectos de suas histórias pessoais às questões teóricas discutidas durante a pesquisa, as participantes deram início a um processo de reflexão acerca de suas identidades profissionais como professoras de línguas estrangeiras.

\section{Que histórias contam os futuros professores de línguas estrangeiras?}

Fundamentado em Clandinin \& Connelly (2000), meu estudo partiu do pressuposto que professores são retentores e produtores de um conhecimento específico, chamado de conbecimento pessoal prático (ELBAZ, 1983; CLANDININ \& CONNELLY, 1995; TELLES, 1999). Connely \& Clandinin (1988) explicam esse conceito da seguinte forma: 
O termo tenta captar a idéia da experiência de modo que ele nos permita falar acerca de professores como pessoas cognoscitivas e sabentes. O conhecimento pessoal prático está na experiência do passado do professor, em sua mente e em seu corpo, presentes em suas ações e planos futuros. O conhecimento pessoal prático é encontrado na prática do professor. Constitui-se, para qualquer docente, em uma maneira peculiar de se reconstruir o passado e as intenções do futuro com o propósito de se lidar com as exigências da situação presente (p.25).

No entanto, poucas são as vezes em que os docentes têm a oportunidade de falar acerca de tal conhecimento e, muito menos, alunas e alunos de Letras. Freqüentemente, esse conhecimento é manifestado dentro da sala de aula por meio da ação pedagógica do professor. No entanto, ele é pouco teorizado ou discutido pelos próprios professores. Para mim, o ato de teorizar ou discutir tal conhecimento é, sobretudo, um ato político emancipador - um ato de tomar a palavra (RANCIÈRE, 1996) e, por meio dela, construir contextos nos quais o professor manifesta suas subjetividades múltiplas como educador e pessoa.

Pelas narrativas apresentadas, pude notar a tomada da palavra pelas participantes. Ao fazê-lo, elas narram tanto os eventos marcantes do processo de reflexão proposto pela Pesquisa Narrativa (CLANDININ \& CONNELLY, 2000) quanto as histórias que contribuíram para a construção de suas identidades como professoras em formação. Nesse processo, as jovens participantes responderam às perguntas: (a) Quem sou eu e o que fez com que eu me tornasse a pessoa que sou na história de minha família? (b) Quem sou eu e o que fez com que eu me tornasse a pessoa que sou na história de minha educação? (c) Quem sou eu e o que fez com que eu me tornasse a pessoa que sou em minha história de aluno de Letras? (d) Quem sou eu e o que fez com que eu me tornasse a pessoa que sou na minha história de aprendiz da língua estrangeira pela qual optei por me graduar como professora? Ao tentarem responder a tais perguntas, as alunas participantes delineiam os constituintes e os processos de constituição de suas subjetividades como pessoas, alunas de Letras e futuras professoras de línguas estrangeiras.

Assim, corroborando os estudos de Connelly \& Clandinin (1999), as participantes estiveram mais interessadas em responder às perguntas relativas às questões de suas subjetividades do que àquelas relativas a conhecimentos específicos das respectivas línguas pelas quais optaram em se graduar. 
Meu desafio foi estabelecer conexões relevantes entre o conhecimento das futuras professoras, o contexto educacional do aluno de Letras - Língua Estrangeira e questões de desenvolvimento da identidade profissional do professor de língua estrangeira.

Passo, em seguida, a responder à primeira pergunta deste estudo. ${ }^{1}$ De maneira geral, para constituírem suas identidades profissionais como professoras de línguas estrangeiras, as alunas se apóiam em bistórias familiares, histórias pedagógicas, histórias de aprendizado de linguas estrangeiras e histórias de profissionalização. Vejamos as características de cada uma dessas histórias.

\section{Histórias familiares}

As histórias mais contadas pelas futuras professoras foram as narrativas acerca de suas relações com a família e seus membros. Tais histórias não somente relatam os eventos marcantes no contexto das relações familiares, mas mostram as reflexões e a repercussão do social, dentro do seio familiar, na constituição de suas identidades. Essas histórias mostram, também, a relação dialética instaurada no processo de subjetivação com o contexto social mais amplo (para além do círculo familiar e suas relações), com a educação e valores (humanos, morais, éticos, religiosos, sexuais) adquiridos fora da instituição escolar e, também, como o desenvolvimento de perspectivas pedagógicas e noções de gênero (como sendo a expressão social do sexo biológico). Por exemplo: nos segmentos, abaixo, retirados das narrativas escritas de duas participantes - Júlia e Patrícia, notamos algumas dessas características desse tipo de histórias (familiares).

Júlia demonstra sua reflexão acerca de questões de gênero e religiosidade, na relação com sua avó, questões acerca do zelo pedagógico na relação com seu avô e conclui seu relato com comentários reflexivos e uma metáfora (ver LAKOFF \& JOHNSON, 1980; TELLES, 1999) acerca do papel transformador do tempo na constituição de sua subjetividade aluna-futura professora de língua estrangeira - a "metáfora do vento e do cata-vento".

\footnotetext{
${ }^{1}$ Em que histórias (fontes de experiências prévias) se apóiam algumas alunas de Letras para constituírem suas identidades profissionais como professoras de línguas estrangeiras?
} 
(...) Quando passava as férias em sua casa, ela [a avó] me convidava para rezar o terço em sua companhia. Muitas vezes, enquanto repetia a seqüência das "Aves Marias", ficava olhando, através da janela, meus irmãos brincando no cafezal. Eu queria tanto brincar com eles, mas precisava rezar o terço.

(...) Era uma manhã de muito sol e vento. Eu estava abaixada no chão e, com um gravetinho, tentava desenhar estrelas na terra, mas não conseguia. Meu avô se aproximou e abaixou-se ao meu lado. Com um outro gravetinho, me ensinou como se desenhava estrelas no chão. $O$ vento forte daquele dia apagou as estrelas do chão, mas não levou as lembranças do meu avô-aquele que me ensinou a desenhar estrelas no chão de terra.

(...) Mas o vento, forte como eu gostava, levou tudo: as brincadeiras de escorregador, as alegrias de tomar sorvete e chupar balas, o medo da professora e das histórias de lobisomem, as imagens dos santos e rezas fortes de minha avó, as estrelas desenhadas no chão pelo meu avô, a infância, o tempo... O vento do tempo precisava girar o cata-vento. (Júlia).

Ao narrar os eventos marcantes de sua vida, Júlia aponta para questões de gênero e religiosidade e se posiciona (ou é posicionada, por sua própria história) como mulher - religiosidade é coisa de meninas, que ficam dentro de casa com a avó, rezando o terço e olhando, pela janela, os meninos brincarem do lado de fora, no cafezal. É posicionada, como criança-menina, por sua própria história, porque queria brincar com os meninos, mas precisava rezar o terço. $\mathrm{O}$ ato de narrar esse evento parece trazer, à sua consciência, tais diferenças de gênero que foram naturalizadas pelo contexto social no qual foi criada.

O segmento seguinte da narrativa de Júlia (o evento com o avô) traz os conceitos de "situação pedagógica", "momento pedagógico" e de "zelo pedagógico", anteriormente tratados por Van Manen (1991). Júlia "tentava desenhar estrelas, mas não conseguia". Para o autor, tal evento se constitui em uma situação pedagógica porque requer uma ação da parte do adulto (p.40), no caso, uma ação da parte do avô. O momento pedagógico é aquele em que o avô se abaixa, pega um graveto e ajuda Júlia a desenhar estrelas, isto é, o avô age (p. 40). Ao agir, o avô mostra o seu zelo pedagógico, isto é, age em favor e cuida da criança, está com ela, a acompanha (p. 37).

O último segmento narrativo de Júlia tem o caráter de síntese ou conclusão e apresenta a metáfora do "vento" e do "cata-vento". Lakoff \& Johnson (1980) transcenderam a visão da metáfora como mero recurso 
lingüístico. Esses autores mostraram que a mesma é uma organizadora de conceitos que representam conhecimentos fundamentados na experiência da pessoa que a usa. Munby (1986) também reconhece que o desvelamento do conteúdo metafórico do discurso dos professores pode fornecer pistas sobre como os mesmos vêem o ensino. No caso de Júlia, o uso da expressão metafórica "O vento do tempo precisava girar o cata-vento" nos fornece pistas acerca da maneira como essa jovem professora conceitua sua própria transformação ao longo de sua vida. Para ela, vento é tempo, cata-vento é experiência e girar é sua própria transformação. O vento (tempo) passa rápido, quase imperceptível e dá impulso, propulsiona, coloca em movimento (faz girar) a experiência (o cata-vento). Seu conceito de transformação parece dinâmico (girar é a razão de ser do cata-vento) e tal experiência (cata-vento) somente se configura ao longo do tempo. Em suma, "o vento do tempo precisava girar o cata-vento" é equivalente à afirmação "O tempo transforma, coloca em movimento, a experiência" - um conceito de transformação, advindo de sua experiência no seio familiar, que pode ter repercussões importantes na sua pedagogia e na constituição de sua identidade como professora.

O segmento da narrativa escrita de uma outra participante Patrícia, além de corroborar essa visão do tempo como importante fator na configuração e transformação da experiência educacional (ver segmento, em itálico, abaixo), ilustra o papel das histórias familiares na constituição de valores, tais como humildade, e do conceito de educação dessa participante. Mas não somente isso. Vejamos:

Quando meu pai disse-me para que eu fosse humilde, não pensou nas crianças que brincavam comigo. Mal sabia ele que, por causa do que havia me dito, prejudicou-me muito. Associei tal humildade ao ato de ficar quieta. Para mim, quando alguém me xingava ou maltratava, eu tinha que ficar calada. Se eu the respondesse alguma coisa, sentia-me como que desobedecendo a meu pai. Hoje, sei que sua intenção era educar-me ou, como seria em sua concepção - "criar-me", mas às vezes nos enganamos. É claro que, com o tempo, redefini o que é bumildade, de acordo com minhas próprias experiências. Isso, sem anular-me diante das pessoas e das situações. As mudanças não ocorreram somente em relação à educação dada por meu pai. Durante esse tempo, percebi que venho pensando acerca dessas questões, que elas ocorreram de diversas formas, minha atitude diante das pessoas... (Patrícia). 
Por meio do segmento, acima, Patrícia também revela o "dano" (RANCIÈRE, 1996), visto por ela como causa dos valores impostos, pelo pai, à sua identidade ("por causa do que havia me dito, prejudicou-me muito"). O excerto também revela o papel do tempo e o caráter mutável (em oposição a "sedimentado") de uma identidade anteriormente construída como humilde e calada, de acordo com as instruções dadas pelo pai. Tais atributos, no entanto, colocaram-na na posição de sujeita aos maus tratos de outras pessoas. Devido ao caráter insustentável dessa história de humildade e silêncio, a ela relegada pela educação paterna como uma virtude e que a faz sofrer, surge sua necessidade de redefinila e viver uma história alternativa - uma história "sem se anular diante das pessoas e das situações". Patrícia corrobora tal história alternativa, ao afirmar, mais abaixo, em uma "carta não enviada" a uma professora, os valores que orientam a sua pedagogia de línguas: voz, espaço e respeito (ver carta nas páginas 69-70).

Assim, os excertos das narrativas das duas participantes, acima, nos dão importantes pistas acerca do papel das histórias familiares na constituição da identidade profissional dessas futuras professoras. Eles nos mostram que a identidade do professor não se constitui unicamente por histórias advindas do contexto da instituição encarregada de formálos como profissionais, mas também por aquelas herdadas e transformadas (na medida do possível) ao longo das vidas dos professores.

\section{Histórias pedagógicas}

Em seguida, temos as histórias pedagógicas, nas quais as alunas relatam suas experiências como aprendizes e os eventos marcantes com seus professores. Tais experiências e eventos estão mais ligados à didática e à formação de valores educacionais e pedagógicos em geral (em contraposição a valores mais específicos, ligados, por exemplo, ao aprendizado de línguas estrangeiras). São histórias relacionadas ao tato pedagógico do antigo professor, ao seu comportamento em sala de aula, às questões relativas às desigualdades sociais na escola, tais como pobreza e abuso de autoridade, à violência para com a criança e à distribuição desigual de poder dentro e fora das salas de aula.

Nos discursos dessas histórias pedagógicas apresentadas pelo grupo de alunas participantes, foram freqüentes certas interrupções reflexivas, nas quais são feitos comentários críticos e de julgamento de 
valores humanos, morais éticos, religiosos e sexuais das participantes (ver segundo e terceiro parágrafos, no exemplo abaixo). Algumas das características dessas histórias pedagógicas são exemplificadas nos seguintes segmentos narrativos, como este, a respeito de abuso infantil e de poder:

(...) A cena de violência de um adulto para com uma criança é angustiante demais para quem pode ser somente o espectador. Espectador é o que eu e as demais crianças éramos naquela sala de aula e no momento em que a professora, irritada, puxou sua aluna pela roupa e colocou-a em pé, numa cadeira que estava em frente ao quadro negro, para que a menina resolvesse o exercício escrito no mesmo quadro, enquanto levava tapas na cabeça. Toda esta violência aconteceu porque a aluna não conseguia aprender as "primeiras lições" e a professora, acreditando que existia uma certa "má vontade" por parte da criança, pensou que a punindo de maneira tão constrangedora, serviria como exemplo para as outras crianças.

Contudo, existiam outros motivos imersos naquele gesto de violência que ultrapassavam os limites da sala de aula. Era de conhecimento de todos nós e da professora que a aluna convivia com os problemas de sua família, que era muito pobre e desestruturada. Por isso, assim como ela, outras meninas com a mesma história moravam num lar especial chamado "A Casa das Meninas". Fazer parte desse lar era uma espécie de rótulo - "É a menina da Casa das Meninas!", o qual permitia, por parte dos professores, distingui-las como "alunas problemas".

Com isso, cada professor resolvia seu problema de maneira que achasse mais correta e conveniente. Isso porque, dificilmente, os pais daquelas meninas reclamariam pelo direito de resolver o problema de suas filhas. (Júlia, 5-6).

Através de uma "carta não enviada" por uma das participantes a uma antiga professora, inferimos certas características da pedagogia desta última - frieza e descaso para com os alunos, rigidez de princípios pedagógicos e intimidação. Nas duas últimas linhas de sua "carta não enviada", a participante Patrícia rejeita essas características do ensino (afirma o caráter insustentável dessa história) e do relacionamento aluno $\mathrm{x}$ professor de sua antiga professora e define o tripé de sua própria pedagogia: voz, espaço e respeito. Vejamos:

Saudações,

Olá professora C.... Talvez a senhora não se lembre de mim, mas eu me lembro muito bem da senhora. Principalmente, quando chegava na sala de aula com aquele seu jeito sério e sem se importar com os seus alunos. 
Será que a senhora se lembra o que me fez? Com certeza, não, pois se não se importou naquele momento, quanto mais agora.

Ainda continua dando aulas? Espero que não tenha feito com nenhum aluno o que me fez. Lembra-se de como me expôs diante da sala? Como agiu?

Como se fosse nossa culpa ter uma professora que não sabia nos ensinar. Seu mal era achar que estava certa. Imagine uma sala formada por um bando de pirralhos. O que poderíamos lhe dizer, não é? Tínhamos muito a lhe dizer, professora. A começar pelas dúvidas em relação à matéria. Isso não era fácil. Quem se arriscaria a lhe perguntar algo? Enfim, hoje estudo para ocupar um lugar como a senhora um dia ocupou. Pretendo ser professora. Mas, acredite: não calarei meus alunos. Darei a eles o que a senhora não nos deu: a voz, o espaço e o respeito. Patrícia

\section{Histórias de aprendizado de línguas estrangeiras}

Nas narrativas escritas pelas participantes, houve, também, as histórias acerca do aprendizado de línguas estrangeiras. Nessas, as futuras professoras relatam os eventos marcantes acerca de suas experiências de primeiro contato com a língua estrangeira, as motivações e a importância de estudá-la, suas noções de "cultura e identidade nacional" e "ser amigo e ser professor amigo", dificuldades e métodos de ensino e aprendizagem, juntamente com comentários críticos e reflexivos acerca de tais experiências. Os últimos dois parágrafos da reflexão narrativa de Júlia, abaixo, mostra sua rejeição da história herdada a respeito do ensino de língua estrangeira e redefine uma história alternativa para vivê-la como aluna de Letras e futura professora de espanhol.

Coloquei todo meu entusiasmo e fantasias dentro de minha mochila, junto com os cadernos e fui para a escola, aprender inglês. Às vezes escutava meu irmão mais velho pronunciar algumas palavras nessa língua que, para mim, eram como se fossem palavras mágicas, códigos secretos que precisavam ser decifrados. Porém, a cada final de aula, meu entusiasmo era abatido pela displicência do conhecimento em língua inglesa que me era oferecido.

Eu queria falar inglês, entender inglês, mas o que "aprendia" era uma lista de verbos e vocabulário. Algumas regras gramaticais que me permitiam construir algumas frases soltas. A minha maior dificuldade era estabelecer conexões entre as diversas formas de se construir frases soltas. As regras gramaticais, as listas de vocabulário e verbos irregulares formavam um todo incoerente que eu não conseguia organizar sozinha. 
É necessário colocarmos nossa marca pessoal nos métodos de ensinar que aprendemos na faculdade porque, muitas vezes, perdemos nossa individualidade nas páginas dos "métodos de língua estrangeira".

Eu necessitava de uma professora que me mostrasse a relação e a diferença entre os diversos tempos verbais, em que tipo de contexto se usa determinado tempo verbal. Perguntas que eu não tinha maturidade intelectual suficiente para abstrair daquele emaranhado de regras gramaticais, mas que comprometeram meu aprendizado.

Os dois últimos parágrafos também dizem respeito aos conceitos de situação, momento e zelo pedagógicos, anteriormente tratados na página 66, acima. O esboço de uma aspecto de sua identidade profissional como professora de língua estrangeira também é, assim, definido. Júlia parece dar indícios de como lidar, como professora de espanhol, com suas futuras situações pedagógicas em sala de aula.

Na história, abaixo, uma participante, Marcela, relata um evento pedagógico no qual teve que lidar com o erro na língua estrangeira na sala de aula. Conclui seu relato com reflexões acerca do papel do professor na garantia de construção de um espaço seguro para que o aluno exercite a prática da língua estrangeira. Da experiência relatada, Marcela também seleciona as histórias que deseja viver na construção de sua identidade profissional. Diferentemente das histórias das outras participantes, as histórias que Marcela seleciona para vivê-las como sua identidade profissional são herdadas de suas professoras de japonês. Isso porque são histórias que garantem espaços para o erro e para o prazer de aprender uma língua estrangeira.

Minha relação com a língua japonesa é muita engraçada. Às vezes eu amo esta língua, porém, às vezes, eu a odeio. As professoras de "nihongo" que já tive sempre me chamavam para responder as perguntas, fazer os exercícios (...). Isto me fazia muito participativa nas aulas. Em uma dessas participações, a professor pediu para eu traduzir a frase: "Watashi ha takusan gohan wo tabemashita". Eu traduzi: "Eu comi arroz com o Taku.". Na hora que disse isso, todos riram muito, mas eu não sabia o porquê. Olhei com bastante atenção à frase e disse: "Ah... está faltando a partícula de companhia ("to"). Mais risadas...

Quando a professora disse que "takusan" não era um nome e que sua tradução era "bastante", eu caí na risada também. A tradução correta era: "Eu comi bastante arroz.".

Esta história não representa algo ruim para mim porque, neste dia, eu me senti aprendendo e nunca mais vou esquecer a tradução de "takusan". É importante dizer aos alunos que se aprende muito com o 
erro e, também, é muito importante o professor saber lidar com os erros dos alunos. Agradeço às professoras de japonês que tive. Elas me mostraram uma sala de aula divertida, onde todos os alunos têm seu espaço e aprendem de uma maneira muito gostosa. Todos se sentem bem em lugares nos quais têm espaços garantidos. Portanto, o professor tem que saber dividir o "espaço" com todos. (Marcela, p.20).

\section{Histórias de profissionalização}

Finalmente, nas histórias de profissionalização, as participantes relatam seus processos de escolha pela língua estrangeira a ser estudada no curso de graduação em Letras, suas relações, conflitos, frustrações e identificação com a instituição universitária como graduandas, as visões de seus professores universitários, da função social dos intelectuais e de seus primeiros passos dentro da academia:

Nunca esquecerei a manhã em que, dentro da sala da diretora, recebia das mãos desta uma inscrição de vestibular que valia, se não me engano, $\mathrm{R} \$ 50,00$ - dinheiro que, na época, eu não teria disponível para o mesmo fim. Neste instante, sem ter muita noção, defini uma série de caminhos para a minha vida. Quando a diretora me perguntou se aceitava aquela inscrição que servia somente para os cursos de Licenciatura, eu respondi que sim. Defini, naquele momento, a universidade que iria estudar, o curso superior que iria fazer, além de optar por não sair de casa, já que o Curso de Letras existe em minha cidade natal. Hoje, tenho consciência que, por trás de meu "sim", existiam pressões sociais que eu não enxergava na época.

No segundo relato, abaixo, a participante descreve o encontro com uma de suas professoras de Língua Japonesa. Nele, ela relata sua dúvida entre optar pela Língua Alemã ou Língua Japonesa, o papel do social nesse processo de identificação com uma dessas línguas estrangeiras para agir profissionalmente e seu peculiar processo de escolha pela profissão de professora de japonês, já que a participante é descendente (terceira geração) de japoneses e, portanto, pode ser identificada por outras pessoas como membro de uma minoria étnica visível e, automaticamente, associada ao grupo étnico e lingüístico. No relato, abaixo, fica claro o fato de que, ao nos relacionarmos com qualquer coisa que nos é estrangeira, as diferenças ficam muito mais explícitas. Por exemplo, no excerto abaixo, é óbvio o papel das identidades fixas e o caráter territorializado das mesmas (você é japonesa, eles são 
alemães, os profissionais alemães são muito exigentes), chegando-se a ponto de discriminação racial:

(...) a outra professora me chamou para conversar num canto e me disse para optar pela língua japonesa, pois os profissionais alemães são muito exigentes. Por isso, seria muito difícil para mim, com esta cara de japonesa, conseguir algum emprego em alguma multinacional ou mesmo na própria Alemanha. (...) Pensei muito acerca disso e, mesmo assim, continuei em dúvida. Até porque havia estudado oito anos na Escola Japonesa do clube de japoneses de minha cidade. Achei que seria a despedida. (...) Percebi que este fato tem uma grande importância em minha formação, pois foi um dos principais motivos que me levou a fazer a opção pela língua japonesa. (...) Sabendo que, na época, eu me encontrava numa situação extremamente confusa e difícil, creio que o papel do professor, alguém com mais experiência e respeitabilidade, foi muito importante na minha formação como futura professora e aluna de Letras. A maneira como um professor age na sala de aula serve como uma base a seus alunos. Sua opinião pode ser crucial. (Mitie, p.12).

O excerto me faz pensar se Mitie não gostaria de ter vivido a história de uma descendente de japoneses que fosse professora de alemão. A identidade territorializada que lhe foi impressa ou "carimbada" por meio da sugestão de carreira dada por sua professora na universidade a fez viver a história herdada pela sua descendência japonesa. Mitie poderia ser uma baiana com cara de japonesa, mas a territorialização de seus traços orientais, impôs-lhe a história de perpetuação dessa identidade racial e retirou-lhe a possibilidade de construir uma história de professora de alemão que é descendente de japoneses.

\section{As participantes respondem ao processo de reflexão} estudo. $^{2}$

Passo, agora, a responder à segunda pergunta de pesquisa deste

\section{Percebendo-se como pessoas e alunas de Letras}

Uma característica marcante tanto das narrativas escritas quanto do processo de pesquisa foi a transmutação das várias maneiras como

${ }^{2}$ Como as alunas participantes respondem à reflexão acerca dos processos de construção de suas identidades como professoras de línguas estrangeiras? 
as participantes se pensavam e se apercebiam como pessoas, alunas de Letras e futuras professoras. As várias oportunidades de reflexão compartilhada (SCHÖN, 1983; PIMENTA \& GUEDIN, 2002) entre as participantes do grupo de pesquisa acerca dos eventos marcantes de suas vidas geraram um processo reflexivo no qual elas podiam mapear (nos termos de GUATTARI \& ROLNIK, 1996 "cartografar") as transmutações, os traços e as características de suas identidades ao longo do tempo, ou seja, em várias fases de suas vidas, até o momento no qual se encontravam. Vejamos como se deu tal processo.

A primeira coisa que eu falei foi acerca de minha família. Contei histórias as quais jamais imaginei contar, com sentimentos que eu nem sabia que estavam lá ainda, mas que eram importantes para minha trajetória pessoal e profissional. Notei que mesmo depois de muito tempo, eu sofria a perda de minha tia e a educação de meus avós ainda me inquietava. Ao mesmo tempo em que sofria, eu mergulhava nas minhas descobertas.

(...) Os "meus" significados tinham elos com minha postura como professora quando ainda lecionava para alunos de primeira a quarta séries e depois, como aluna de Letras, futura professora de Língua Espanhola. A maneira como eu construí a minha concepção do que era ser professora estava entrelaçada com minha história de vida: com meus avós, com minha tia, com a religiosidade, com questões de gênero.

A busca "por mim" acabou me colocando a caminho do magistério, onde aos poucos, eu encontrei algumas peças para o quebra-cabeça de minha subjetividade como professora. Foi no curso de magistério, através das disciplinas de história, sociologia, psicologia e filosofia que tomei consciência dos cruzamentos dos discursos que atravessavam a minha formação e formavam a minha visão de mundo. E foi na mescla da identificação e do tomar consciência dos aspectos que compunham minha subjetividade é que eu constituía como professora. (Bruna, p. 4-6).

O que pude perceber durante o processo de pesquisa foi que "tornarse professora" era como uma escolha dentro das várias subjetividades que me compunham. (Bruna, p. 8).

(...) Percebo que, em quase todas as histórias, aparece uma Marcela querendo ser o centro, querendo seu espaço, a irmã mais nova, a dona da gaveta, a dançarina, a noiva, a que pula muros, a professora, a pesquisadora que participa de congressos. O grupo ajudou-me a perceber que me sinto bem quando tenho este espaço garantido e, principalmente, quando sou o centro - outro motivo pelo qual eu escolhi ser professora. O professor tem a atenção dos alunos, o professor está no centro. (Marcela, p. 24). 
Os três excertos acima, sugerem que o processo reflexivo acerca da identidade profissional é complexo. Bruna aponta para o seu sofrimento e para sua característica de processo que exige atenção e reflexão (quebra-cabeças). Ela também percebe entrelaçamentos entre o aspecto privado de sua vida familiar e o aspecto social de seu trabalho como professora. Bruna também menciona uma "busca por mim", revelando seu esforço para resolver o quebra-cabeça de sua identidade profissional.

Marcela, por sua vez, se mostra consciente de que está vivendo histórias herdadas de sua relação com a irmã, assim como suas próprias histórias de transformação, as quais, naquele momento de escrita da narrativa, exigiam um espaço no qual ela pudesse ser o centro de atenções, relacionando tal necessidade pessoal com a figura da professora - uma relação, talvez, não apropriada, mas que revela sua tentativa de construção de um todo plausível para se compreender como profissional.

\section{Susto frente a um novo paradigma de pesquisa}

Em algumas ocasiões, as participantes se sentiram inseguras quanto à metodologia de pesquisa adotada. Cada uma delas trouxe para o grupo de pesquisa conceitos acerca do que é e o que não é científico, conceitos esses geralmente tendendo a paradigmas positivistas de pesquisa em educação, à existência de uma verdade única e à validação dos achados em sintonia com o conhecimento já produzido (ver DENZIN \& LINCOLN, 1998). Houve, portanto, conflito entre as concepções que as participantes traziam acerca do que é pesquisa e o que é científico e as propostas de trabalho do coordenador do projeto.

Quando entrei no grupo, fiquei entusiasmada com a proposta de trabalho do professor-coordenador com alunos de Letras, futuros professores de línguas estrangeiras. Contudo, quando soube que teria de contar a minha história, senti-me confusa. Não conhecia este paradigma de pesquisa que trabalha com histórias de vida. (...) Achei, no início, que não era muito "científico" falar de minha vida. Quando conheci mais profundamente o caráter da pesquisa, deparei-me com um trabalho sério e complexo. (...) Durante um bom tempo, fiquei perturbada com minhas questões. Saía das reuniões com dores de cabeça. A gente, ali, mexia muito com questões pessoais. Éramos futuras professoras com pouca experiência de vida. Muitas dúvidas, muitos medos...Mesmo assim, eu contei a minha história”! (Bruna, p.2-3). 
O excerto de Bruna acima também revela uma reação de participante em relação à pesquisa narrativa que sempre tento encarar com cautela - um certo "tom confessional" da participante em relação a "ter que contar" (veja no excerto) sua narrativa de vida para o grupo. Visto por Bruna tal como uma obrigação, o fato de "ter de contar sua vida" lhe causa dúvidas e medo (ver as últimas linhas do excerto). Como pesquisador que utiliza essa metodologia de pesquisa, sempre assinalo às participantes que não se sintam na obrigação de oferecer os fatos marcantes de suas vidas tal como se oferecesse cafezinho em uma bandeja. Uma regra básica a ser seguida é a seguinte: não contar histórias que causarão sensação de desconforto às participantes, a menos que se sintam em condições de enfrentar ou lidar com tal tipo de sensação. A última frase do excerto ("Mesmo assim, eu contei a minha história!") parece revelar a determinação da participante para lidar com os seus próprios medos e inseguranças. O "tom confessional" de Bruna, no entanto, permanece. Devo dizer que, como pesquisador, tal fato não me agrada, pois confissão implica culpa, julgamento e passividade e tais características não me parecem em sintonia com os objetivos da pesquisa narrativa.

\section{Trajetórias pessoais e escolhas pedagógicas}

Uma participante também é capaz de estabelecer relações entre a atividade principal da pesquisa narrativa com a prática de sala de aula. Afirma que os atos de escolha dos professores estão entrelaçados com suas trajetórias pessoais de desenvolvimento.

Qual a relação disto tudo com o ensino da língua estrangeira? Contar histórias, por vezes, nos parece algo distante das nossas salas de aula, ou melhor, nos parecia. Somos professores ao mesmo tempo em que somos pessoas. Isto implica que quando estamos em nossas salas de aula, com nossos alunos, trabalhando certos conteúdos, estamos fazendo isto por um viés bastante pessoal. (Bruna, p. 11).

\section{Construção da Identidade Profissional e conhecimento codificado nos livros}

No processo de constituição das identidades profissionais de professoras pelas alunas participantes, as teorias e o conhecimento codificado nos livros têm, também, sua participação. No processo 
reflexivo, engatilhado pelo contar e recontar as histórias marcantes de suas vidas, as participantes puderam articular os conteúdos e os autores lidos na constituição de suas crenças acerca do ensino e a nova profissão de professora de línguas. Tais características podem ser observadas no segmento da narrativa abaixo, de uma participante que já tinha experiência de magistério no terceiro e quarto ciclos do Ensino Fundamental:

Percebi que, nas minhas aulas e na maneira como eu tratava meus alunos, reproduzia muito do que eram os meus professores e perpetuava suas atitudes, as quais eu mesma contestava. (...) Isso me inquietava muito porque a ideologia, segundo Maria Helena Chauí, está intimamente ligada aos "pensamentos" da elite. O discurso com o qual eu me identificava não era este, o da elite. Eu me identificava com o "discurso dos oprimidos", aquele do qual o educador Paulo Freire falava. Por ter vindo da mesma origem que meus alunos, passado pelas mesmas dificuldades para estudar, nem sempre podendo ter acesso aos melhores livros, escolas, etc. eu formei a minha concepção do que era "ser professora". (Bruna, p. 13-14).

\section{Cursos de Letras: formando uma identidade profissional}

As participantes também enfatizam a importância do processo de Pesquisa Narrativa como contexto de reflexão e construção de novos conceitos acerca da profissão e o papel do professor de línguas estrangeiras. Também criticam os cursos de Letras quanto ao desenvolvimento e conscientização desses novos papéis para a vida profissional dos alunos.

Acredito que o aprofundamento reflexivo das histórias contadas está intrinsecamente ligado à nossa vontade de transformar aquilo que fizeram da gente (repetindo a formulação sartriana). Em que podemos, a partir das histórias que nos constituem, construir um novo conhecimento das nossas experiências. Um conhecimento que sempre estará na gênese de nossas decisões em sala de aula. (...) Nesse sentido, gostaria de ressaltar a importância deste tipo de trabalho nas instituições que formam professores. Infelizmente, estas se preocupam apenas com que o professor em formação domine uma série de conteúdos a respeito de determinada disciplina, para que, nas avaliações, este repita aquilo que todo mundo já sabe. Deste modo, a quantidade de informações aumenta, mas a visão de mundo e do campo de atuação intelectual do professor em formação é muito limitada. Ele não tem noção que pode 
construir pensamentos, opiniões e novos conhecimentos com essas informações.

(...) Ao professor em formação de língua estrangeira é ensinado um poderoso instrumental gramatical, para que ele ensine seus futuros alunos. Mas não the é ensinado que o professor pode abordar um discurso social contido em um texto em língua estrangeira e que o próprio ensino de língua estrangeira, per se, é uma grande questão de poder social que deve ser abordada em sala de aula pelo professor. (Júlia, p. 33-34).

\section{Pareço, sou e não sou japonesa}

O processo de reflexão deflagrado pela Pesquisa Narrativa também pode suprir um contexto para que uma das participantes, descendente de japoneses, pudesse refletir acerca de sua identidade étnica, suas relações com a língua e comunidade japonesas no Brasil, sua opção pela profissão de professora de Língua Japonesa e seus critérios para suas futuras ações pedagógicas.

Em minha vida, houve vários episódios em que eu ficava sem graça devido à diferença física. Na infância, freqüentemente me pediam para falar alguma coisa em japonês ou "fechar os olhos". (...) Em conseqüência, fechei-me num "ciclo fechado" de amizades. Hoje, agiria de uma outra forma. O amadurecimento me fez dar menos importância a certos acontecimentos. (...) Além de pensar acerca de minha maneira de agir como aluna de japonês, penso sobre minha futura prática como professora desta língua. Assim como se leva muitos anos para descobrir a cura de algumas doenças, levei anos para compreender que, independentemente de minha diferença física, sou como as demais, ou seja, sou brasileira. É realmente difícil se sentir brasileira quando a diferença é tão visível. Sou chamada de japonesa por qualquer um que me veja. (Mittie, p. 16-21).

\section{Comentários finais}

Como relatam as participantes em suas narrativas, a experiência de ter passado pelo processo de pesquisa forneceu-lhes um contexto, sem dúvida, especial e profícuo para a reflexão e desenvolvimento profissional no curso de graduação. Quase seis anos após o início da pesquisa, as seis alunas que concluíram o processo estão todas engajadas em algum tipo de trabalho acadêmico ou profissional no presente momento, tais 
como pesquisas em nível de iniciação científica e mestrado, práticas pedagógicas em centros de línguas, intercâmbios culturais com países de suas respectivas línguas estrangeiras de trabalho e conclusões de dissertações de mestrado. Nossa experiência de três anos de trabalho proporcionou elos marcantes de ligações pessoais entre as integrantes do grupo, os quais ainda permanecem anos após a finalização dos trabalhos. Como metaforicamente relatam Clandinin \& Connelly (2000), quando iniciamos a Pesquisa Narrativa, já pegamos os bondes das vidas das participantes andando. Permanecemos por um certo tempo a bordo e, eventualmente, ao término do período de pesquisa, descemos do bonde para que ele continue sua viagem. Esse período de finalização da pesquisa se constituiu somente em uma etapa do desenvolvimento das alunas participantes. O processo de pesquisa não se encerrou aí. Possivelmente, ele continua sendo realizado pelas próprias alunas, no presente momento, quando já concluíram o curso de Letras e atuam no mercado de trabalho. É possível verificar tal fato por meio daquelas participantes que permaneceram próximas, ou vivendo na mesma cidade ou ainda presentes em meus grupos de pesquisa, sendo orientadas em programas de pós-graduação em nível de mestrado. As repercussões desse processo de pesquisa iniciado logo no primeiro ano do curso de graduação são perceptíveis em suas atuais pesquisas e relatos acerca de suas vidas profissionais.

O processo de pesquisa e de escrita das narrativas favoreceu, também, oportunidades para a tomada de palavra (RANCIÈRE, 1996) das jovens participantes. Ao recobrar os eventos marcantes de suas vidas e relatar aqueles que achassem que deveriam relatar ao grupo, as alunas se posicionaram frente aos eventos em posições de denúncias, questionamentos, críticas, reflexões, reconstruindo o significado dos mesmos para si próprias e reformulando quadros de referências (corpos de significados) entre o significado do que haviam experienciado e a constituição de suas identidades profissionais de alunas de Letras e futuras professoras de línguas estrangeiras.

Nas histórias familiares, as participantes recuperaram os significados dos eventos de infância e das experiências familiares e os reconstruíram para vivê-los no presente, de formas alternativas, levando-os em conta em suas formações como pessoas e futuras professoras. São significados de zelo e reavaliações de crenças religiosas, as quais foram culturalmente assimiladas para dar explicações a eventos educacionais e da vida cotidiana. A reflexão compartilhada pelo grupo acerca das histórias de 
vida relatadas proporcionou às participantes contextos para localização de si próprias, em termos de gênero e dos valores sociais que lhes foram passados, de maneira não-crítica, pelas respectivas culturas nas quais foram criadas.

As histórias pedagógicas requereram um posicionamento das participantes face aos eventos marcantes de ensino e de aprendizagem e, também, face à didática experienciada em suas vidas, como alunas. Nesses relatos reconstruídos a partir de suas experiências, as alunas reconstruíram as referências de professores passados e engendradas de forma passiva e sem muitas críticas (as histórias herdadas), discutiram tais referências e perceberam que as histórias destes últimos não podiam mais ser sustentadas. Partiram, então, para buscar outros contrapontos ou alternativas àqueles que lhes foram disponibilizados ao longo da educação escolar. Se nos lembrarmos que Connelly \& Clandinin (1999) nos apresentam uma noção de identidade como "histórias pelas quais vivemos" ou como "construções narrativas que adquirem formas no desenrolar de nossas vidas", podemos dizer que, ao buscar uma organização de suas narrativas que lhes pareça plausível e harmônica, as participantes reavaliam as histórias herdadas e partem para viver outras mais condizentes com os seus desejos.

Nas histórias de aprendizado de línguas estrangeiras, as alunas buscaram as motivações para suas opções profissionais, o questionamento dos métodos utilizados por seus antigos professores e denunciaram os danos (RANCIÈRE, 1996) a elas causados pelo ensino sem propósito de línguas estrangeiras. Dessa forma, seja pela rejeição ou aceitação de modelos (histórias herdadas) de ensino/aprendizagem de LE aos quais foram expostas, as participantes puderam refletir acerca de tais questões, sempre estabelecendo ligações com a formação profissional.

Nas histórias de profissionalização, em função de suas experiências educacionais anteriores, as alunas relataram suas buscas por modelos profissionais nos quais acreditam. Rejeitaram, no entanto, certas referências e elegeram outras alternativas, construídas por meio da reflexão proporcionada pelo contexto da pesquisa.

Finalmente, no que diz respeito ao processo de reflexão compartilhada proporcionado pela Pesquisa Narrativa, as participantes se perceberam como pessoas e alunas de Letras e as possíveis ligações entre esses dois modos de existência. Falaram acerca de sua relação com o tipo de pesquisa realizada, suas trajetórias pessoais nas escolhas 
pedagógicas, suas relações com o conhecimento codificado nos livros e as formações de identidades profissionais e nacionais.

Como em Catani (2001), o trabalho ressaltou "a necessidade da iniciação do professor passar pelo conhecimento do que acontece com ele próprio" (p.60) e, também, "a necessidade de pensar a atuação do professor do ponto de vista das significações pessoais assumidas no exercício da docência" (p.61). No caso de Mitie, uma descendente de japoneses, é possível notar o papel impositivo de uma identidade profissional territorializada pelas práticas sociais de seu meio. Se, como colocado anteriormente na parte teórica deste trabalho, "identidades são histórias pelas quais vivemos" (CONNELLY \& CLANDININ, 1999), Mitie é impedida de viver a sua própria como professora, descendente de japoneses, que ensina a língua alemã. De fato, a pesquisa pode evidenciar tais solidificações de entidades fixas herdadas do social na construção das identidades profissionais dos professores. Um outro exemplo foi o caso de Júlia e sua relação com a religiosidade e com as questões de gênero de suas histórias familiares. Esse caso ilustra o fato de que a subjetividade é, de fato (como em GUATTARI \& ROLNIK, 1996), um agenciamento coletivo de enunciação, um conjunto de sinais, signos, símbolos (as Aves Marias da avó, menina rezando o terço, menino brincando no cafezal) que se constroem coletivamente em cada cultura, em diferentes contextos históricos. No entanto, a pesquisa não serviu somente para confirmar essas questões. Ela nos mostrou que o processo reflexivo da pesquisa narrativa abre espaços de interação nos quais esses sentidos cristalizados no tempo e no espaço são questionados e que tais identidades herdadas são desterritorializadas, desmanchadas e atravessadas por outros níveis de composição da subjetividade, para que a participante da pesquisa pudesse resignificar tais conceitos e viver as histórias que desejassem viver (como Mitie gostaria de viver sua história de professora de alemão). Esse processo transformador também é ilustrado por meio da participante Patrícia, quando questiona a história de humildade a ela imposta por seu pai.

Assim, se a pesquisa não contribuiu para uma concepção definida de professora de línguas estrangeiras, acredito que ela possa ter contribuído para uma maior conscientização das múltiplas possibilidades de ser aluna de Letras e professora de língua estrangeira. 


\section{Referências Bibliográficas}

CATANI, D. B. A didática como iniciação: Uma alternativa no processo de formação de professores. In: CASTRO, A.D.; CARVALHO, A.M.P. Ensinar a ensinar: Didática para a escola fundamental e média. São Paulo: Pioneira, Thomson Learning, 2001.

CLANDININ, D.J.; CONNELLY, F.M. Teachers' Professional Knowledge Landscapes. New York: Teachers' College Press, 1995.

CLANDININ, D.J.; CONNELLY, F.M. Narrative Inquiry. New York: Teachers College Press, 2000.

CONNELLY, F.M.; CLANDININ, D.J. Teachers as Curriculum Planners: Narratives of experience. New York: Teachers College Press, 1988.

CONNELLY, F.M.; CLANDININ, D.J. Stories of experience and narrative inquiry. Educational Researcher, v.19, n.5, p. 2-14, 1990.

CONNELLY, F.M.; CLANDININ, D.J. Shaping a Professional Identity: Stories of educational practice. New York: Teachers College Press, 1999.

DENZIN, N.K.; LINCOLN, Y.S. (Ed.). The Landscape of Qualitative Research: Theories and issues. Thousand Oaks, Ca.: Sage Publications, 1998.

ELBAZ, F. Teacher Thinking: A study of practical knowledge. London: Croom Helm, 1983.

GADAMER, H. Truth and Method. New York: Crossroad Publishing Company, 1986.

GLESNE, C.; PESHKIN, A. Becoming Qualitative Researchers. New York: Longman, 1992.

GUATTARI, F.; ROLNIK, S. Cartografias do desejo. Petrópolis: Vozes, 1996.

LAKOFF, G.; JOHNSON, M. Metaphors We Live By. Chicago: University of Chicago Press, 1980.

MUNBY, H. (1986) Metaphors in the thinking of teachers: An exploratory study. Journal of Curriculum Studies, 18(2), 197-209.

PIMENTA, S.G.; GUEDIN, E. Professor reflexivo no Brasil: Gênese e crítica de um conceito. São Paulo: Editora Cortez, 2002.

RANCIÈRE, J. O desentendimento. São Paulo: Editora 42, 1996. 
RICOEUR, P. Time and narrative. Chicago: University of Chicago Press, 1984. V. 1.

SCHÖN, D. The Reflective Practitioner. Basic Books, Inc. 1983.

SCHWANDT, T. A. Constructivist, interpretivist, approaches to human inquiry. In: DENZIN, N.K.; LINCOLN, Y.S. (Ed.). The Landscape of Qualitative Research: Theories and issues. Thousand Oaks, Ca: Sage Publications. 1998. p. 221-259.

TELLES, J. A. O professor de línguas estrangeiras e seu conhecimento pessoal da prática: princípios e metáforas. Linguagem e Ensino, v.2, n.2, p. 29-60, 1999.

TELLES, J. A. Biographical connections: Experiences as sources of legitimate knowledge. QSE- International Journal of Qualitative Studies in Education, 13, n. 3, p. 251-262, 2000.

TELLES, J.A. A trajetória narrativa. In: GIMENEZ, T. (Org.). Trajetórias na Formação do Professor de Linguas. Londrina: Editora da Universidade Estadual de Londrina, 2002a.

TELLES, J.A. É pesquisa, é? Ah, não quero não, bem! Sobre pesquisa acadêmica e sua relação com a prática do professor de línguas. Linguagem EEnsino, v. 5, n. 2, p. 91-116, 2002b.

Van MANEN, M. Researching Lived Experience. London, Ontario: The Althouse Press, 1990.

Van MANEN, M. The Tact of Teaching: The meaning of pedagogical thoughtfulness. London, Ontario: The Althouse Press, 1991. 